\title{
Asymptomatic double aortic arch diagnosed incidentally in an adult patient
}

\author{
Zeynep Aslan Yağlı \\ Department of Cardiovascular Surgery, Kocaeli Health Sciences University, Derince Training and Research Hospital, Kocaeli, Turkey \\ Received: March 27, 2021 Accepted: July 10, 2021 Published online: August 11, 2021
}

\begin{abstract}
Vascular rings are rare major congenital vascular anomalies characterized by a complex anatomical anomaly of the aortic arch and associated with the vascular structures surrounding the trachea and esophagus like a ring. Symptoms usually occur in infancy or early childhood. Diagnosis in adult age is extremely rare. In this article, we present a rare adult case of double aortic arch diagnosed incidentally.

Keywords: Adult, asymptomatic, double aortic arch, vascular ring.
\end{abstract}

Vascular rings, which account for less than $1 \%$ of congenital heart diseases, ${ }^{[1]}$ were first described by Gross $^{[2]}$ in 1945. In double aortic arch (DAA), due to errors in the regression of the right aortic arch, both aortic arches form a vascular ring that completely surrounds the trachea and esophagus. Each aortic arch passes superior to the main bronchus on the same side and enters the descending aorta, often localized on the left with respect to the right side of the spine. In most cases, this anomaly is diagnosed in infancy or childhood, depending on the symptoms caused by esophagus and tracheal obstruction. Diagnosis in adults, particularly in asymptomatic cases, is extremely rare. ${ }^{[3]}$ Herein, we present a rare adult case of DAA diagnosed incidentally.

\section{CASE REPORT}

A 42-year-old male patient with a diagnosis of schizophrenia was admitted to our clinic with non-specific chest and back pain. Physical examination and laboratory tests were normal. Chest radiography showed bilateral aortic notches at the level of aortic arch (Figure 1). Three-dimensional (3D) computed tomography (CT) angiography, a non-invasive test that provides high-quality 3D imaging, revealed nearly same sized DAA. Brachiocephalic truncus was not seen. The right common carotid artery and the right subclavian artery were originating from separate roots from the right aortic arch. The left common carotid artery and left subclavian artery were originating from separate roots from the left aortic arch (Figure 2). At the junction of the arches on the posterior, the esophagus was minimally compressed between the trachea and the arch (Figure 3). However, since our patient did not have respiratory and nutritional disorders due to

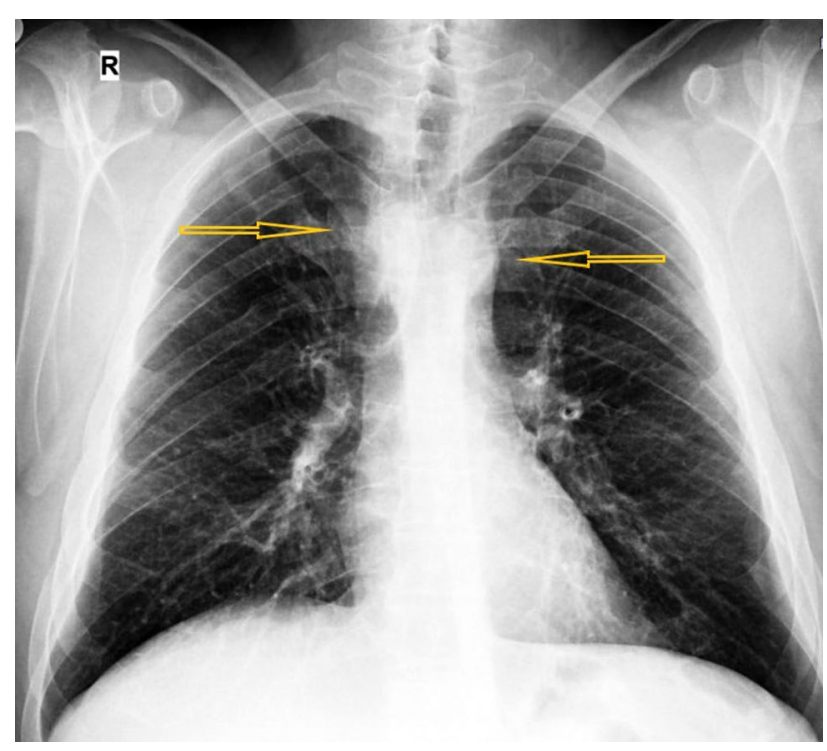

Figure 1. Chest radiography showing bilateral aortic notches.

Corresponding author: Zeynep Aslan Yağll, MD. Kocaeli Sağllk Bilimleri Üniversitesi, Derince Eğitim ve Araştırma Hastanesi Kalp ve Damar Cerrahisi Kliniği, 41900 Derince, Kocaeli, Türkiye.

Tel: +90 262 - 3178000 e-mail: kvc.dr.zeynepaslan@gmail.com

\section{Citation:}

Aslan Yağlı Z. Asymptomatic double aortic arch diagnosed incidentally in an adult patient. Cardiovasc Surg Int 2021;8(2):119-121. 

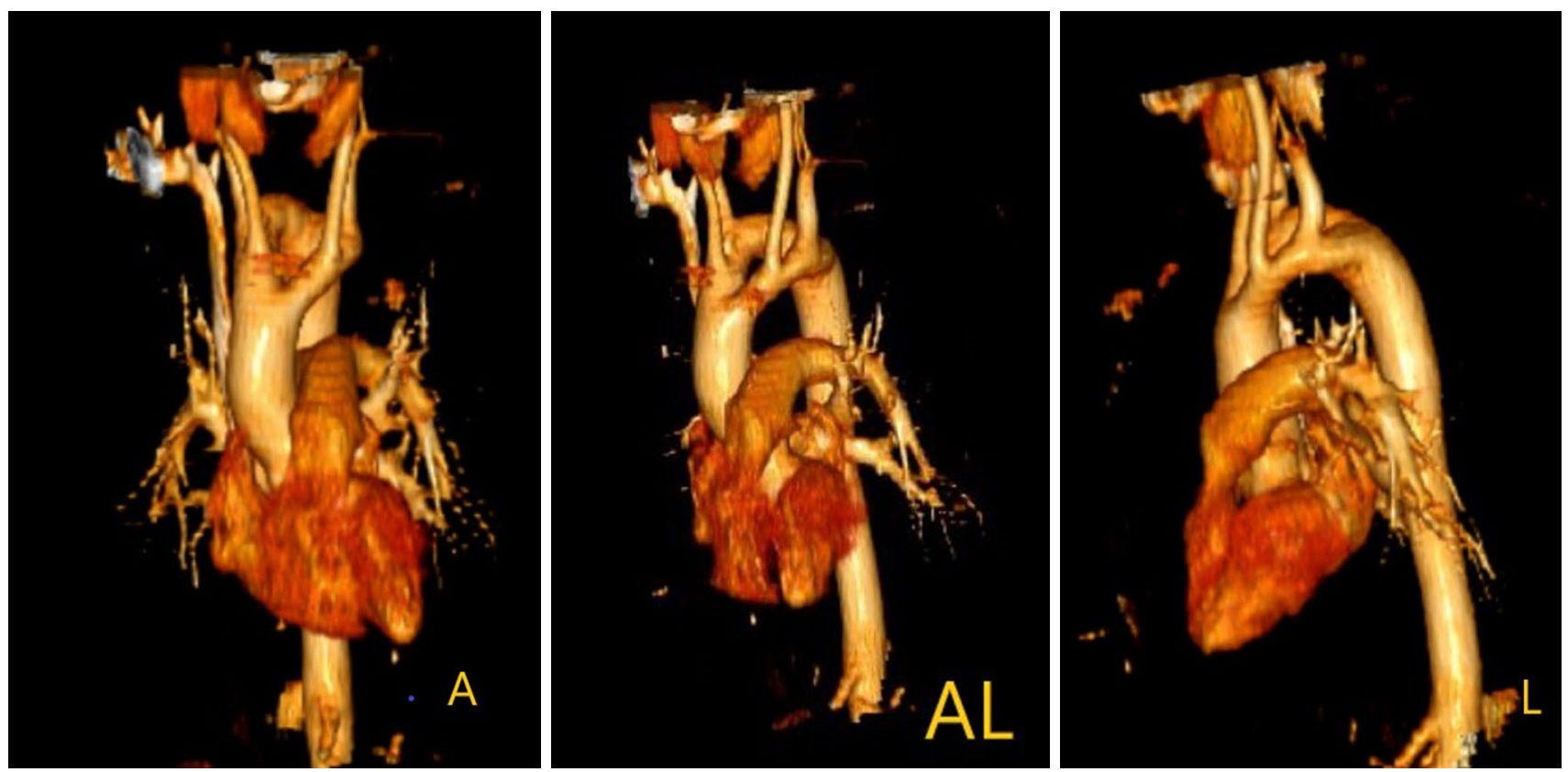

Figure 2. Multislice computed tomography showing a vascular ring; anterior, anterolateral and lateral view.
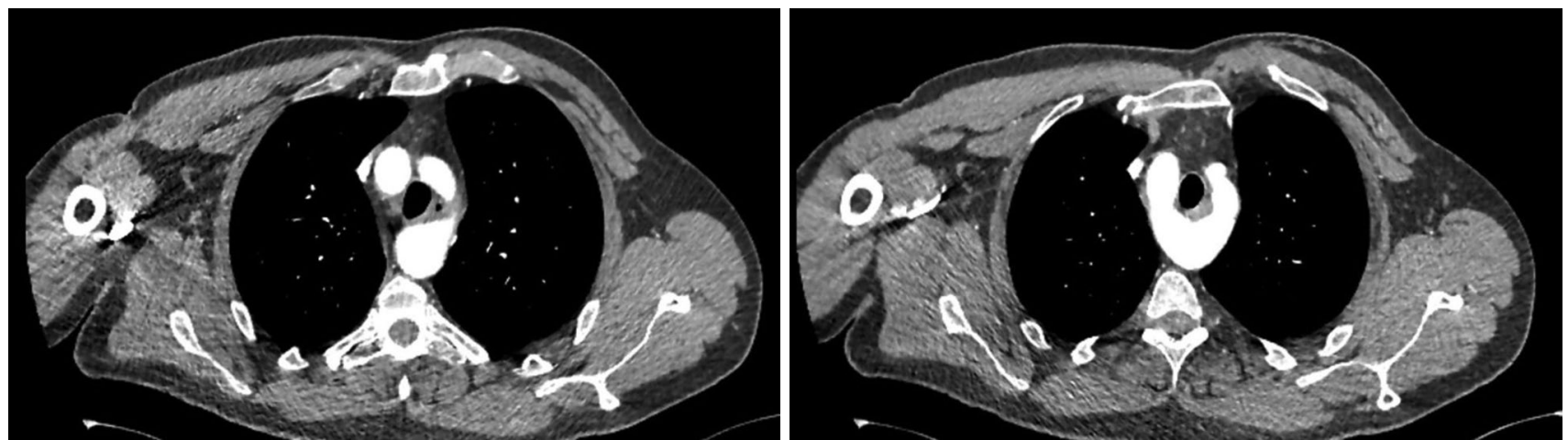

Figure 3. The esophagus is minimally compressed between trachea and arch.

DAA, the cause of his complaints was investigated, and he was also evaluated by the cardiology and chest diseases departments. However, no organic reason was able to be found. Considering that he had non-specific complaints related to schizoaffective disease, he was referred to the psychiatry clinic. He was also regularly scheduled for follow-up in the cardiovascular surgery outpatient clinic. A written informed consent was obtained from the patient.

\section{DISCUSSION}

Double aortic arch, the most common form of vascular rings, is a congenital anomaly that occurs, when the ascending aorta is divided into two parts and passes around the trachea and esophagus and, then, turns into a single pattern aorta. ${ }^{[4]}$

The embryological development of the vascular ring has been described in detail in the literature. In the embryonic arch system, there are six parts of the aortic arch originating from the ventral aortic root. The first, second, and fifth arches regress and a DAA is formed. In general, the left fourth arch forms the aortic arch. If the left fourth arch regresses and the right arch remains, this results in a right-sided aortic arch. ${ }^{[4]}$ In DAA, due to errors in the regression of the right aortic arch, both aortic arches form a vascular ring that completely surrounds the trachea and esophagus. Classically, 
there are three types of DAA: right dominant aortic arch, left dominant aortic arch, and balancedtype aortic arch. In $75 \%$ of cases, the right arch is dominant and, in about $20 \%$ of cases, the left arch is dominant. In $5 \%$ of the cases, both arch dominance is equal. ${ }^{[5]}$ In our case, the patient had a balanced-type aortic arch.

Double aortic arch may cause compression of these structures by surrounding the trachea and esophagus. Symptoms such as respiratory distress, feeding difficulties, recurrent pneumonia, stridor and dysphagia may occur as a result of tracheal and/or esophageal compression at birth and in early infancy. ${ }^{[6]}$ However, partial compression may show an asymptomatic course, as in our patient.

Chest X-ray may be normal and diagnosis may be missed. Various imaging methods, such as magnetic resonance imaging (MRI), CT scanning, and aortography, can be used to reveal DAA and determine the most optimal surgical approach for surgical candidates. ${ }^{[7]}$

The presence of symptoms for vascular rings is a surgical indication at all ages. In particular, adults without symptoms may not need surgery. Nevertheless, we argue that, cases similar to our patient may need a close follow-up with regular laboratory studies and proper physical examination. Surgical delay may cause serious morbidity and irreversible complications of the respiratory system, leading to death even. ${ }^{[8]}$ Medical therapy is a choice that can contribute to surgical treatment. Surgery for aortic arch division can be accomplished through a right or left thoracotomy and it can reach out to relieve tracheoesophageal structures. Maximum effort is required to avoid vascular and neighboring structures for acceptable postoperative results. Despite this, long-term surveillance after surgery is 90 to $95 \%$ of all cases. Particularly asymptomatic adults may not need surgery. ${ }^{[8]}$
In conclusion, although double aortic arch is well described in childhood it is rare in adult patient because of its asymptomatic course. Surgery may be necessary if it causes symptoms due to tracheal and esophageal compression otherwise patients should be followed up under regular medical follow-up.

\section{Declaration of conflicting interests}

The author declared no conflicts of interest with respect to the authorship and/or publication of this article.

\section{Funding}

The author received no financial support for the research and/or authorship of this article.

\section{REFERENCES}

1. Atay Y, İyem H, Yağdı T, Alayunt EA. Double arcus aorta: Diagnosis and surgical treatment. Turk Gogus Kalp Dama 2001;9:250-2.

2. Gross RE. Surgical relief for tracheal obstruction from a vascular ring. N Engl J Med 1945;233:586-90.

3. Seo HS, Park YH, Lee JH, Hur SC, Ko YJ, Park SY, et al. A case of balanced type double aortic arch diagnosed incidentally by transthoracic echocardiography in an asymptomatic adult patient. J Cardiovasc Ultrasound 2011;19:163-6.

4. Yilmaz M, Tok M, Cengiz M. Asymptomatic balanced-type double aortic arch in an elderly patient: A case report. Heart Surg Forum 2007;10:E297-8.

5. Seo HS, Park YH, Lee JH, Hur SC, Ko YJ, Park SY, et al. A case of balanced type double aortic arch diagnosed incidentally by transthoracic echocardiography in an asymptomatic adult patient. J Cardiovasc Ultrasound 2011;19:163-6.

6. Sariaydin M, Findik S, Atici AG, Ozkaya S, Uluisik A. Asymptomatic double aortic arch. Int Med Case Rep J 2010;3:63-6.

7. Kondo C, Takabayashi S, Miyake Y, Onoda K, Shimpo H, Yada I. Successful surgical treatment for an adult case of double aortic arch. Jpn J Thorac Cardiovasc Surg 2005;53:223-6.

8. Talay S, Belgit Talay N, Kaygın MA, Dağ Ö, Erkut B. Adult incidental asymptomatic symmetrical double aortic arch case as a variation of congenital vascular ring malformation. Turkiye Klinikleri J Cardiovasc Sci 2013;25:49-52. 